\title{
La impugnación internacional de resoluciones jurisdiccionales en materia del derecho humano a la seguridad social
}

El 1\% de la población disfruta de las mejores viviendas, la mejor educación, los mejores médicos y el mejor nivel de vida, pero hay una cosa que el dinero no puede comprar: la comprensión de que su destino está ligado a cómo vive el otro $99 \%$. Conocemos ya las consecuencias de la desigualdad: altos índices de criminalidad, menores niveles de educación, de cohesión social y de esperanza de vida.

Joseph E. Stiglitz

\section{Ángel Guillermo Ruiz Moreno* Ángel Edoardo Ruiz Buenrostro**}

Recibido: 23 enero 2017

\begin{abstract}
Resumen
En este mundo globalizado en todos los órdenes, uno de los reclamos más sentidos por la ciudadanía es sin duda el respeto irrestricto por parte del Estado a los derechos humanos, y en caso de su eventual inobservancia por cualquier motivo, lograr una eficiente administración de justicia que garantice tales derechos en todo tiempo y lugar.

La constante discrecionalidad por los Poderes Públicos en su pleno respeto, así como la manera de interpretar los alcances de la seguridad social, en realidad muy poco abonan para generar una genuina cultura de la seguridad social, para colmo uno de los derechos humanos menos estudiado y conocido por la colectividad. Ese complicado problema estructural, si no es posible repararlo adecuadamente ante tribunales nacionales, debe ser controlado al través del uso cotidiano de los mecanismos legales de defensa consagrados en los Tratados Internacionales, acudiéndose en caso necesario a instancias y jurisdicciones internacionales.
\end{abstract}

\footnotetext{
*Universidad de Guadalajara. agruizm@ruizmoreno.com
}

**Universidad de Guadalajara. aeruizb@gmail.com 
Palabras clave: Protección social genérica, seguridad social, derechos humanos, justicia social, tratados internacionales, normatividad internacional aplicable.

\title{
The international challenge of jurisdictional resolutions regarding the human right to social security
}

\begin{abstract}
In this globalized world at all levels, one of the demands most deeply felt by the public is certainly the unrestricted respect for human rights by the State, and in case of their eventual failure to comply for any reason, to ensure an efficient administration of justice that guarantees such rights in all time and place.

The constant discretionality by the public powers in their full respect, as well as the way to interpret the scope of social security, in fact does very little to generate a genuine culture of social security; on top of everything, among the least studied and known human rights. That complicated structural problem, if it is not possible to properly address before domestic courts, must be controlled through the everyday use of legal defense mechanisms enshrined in international treaties, turning up to international institutions and laws if necessary.

Key words: Generic social protection, social security, human rights, social justice, international treaties, applicable international standards.
\end{abstract}

\section{Sumario}

I. Contexto general latinoamericano de la seguridad social actual. II. La débil justicia nacional y latinoamericana en temas de la seguridad social, entendida como un derecho humano. III. La normatividad internacional de seguridad social vigente en la mayor parte de América Latina. IV. La impugnación de las resoluciones jurisdiccionales de seguridad social ante organismos internacionales de derechos humanos. V. Conclusiones. Bibliografía.

\section{Contexto general latinoamericano de la seguridad social actual.}

Unos de los más grandes desafíos que afronta hoy día la seguridad social nacional, tanto en México como en América Latina entera, es la débil impartición de 
justicia en un rubro que tanto preocupa a la ciudadanía, como lo es la seguridad social, ya sea por la manera en cómo se sigue concibiendo ésta a manera de una simple extensión o apéndice del Derecho del Trabajo, acaso al estar atado su radio de acción primordialmente a la protección de los trabajadores subordinados y de sus familias - lo que genera frecuentes confusiones con la figura jurídica de la previsión social laboral-, o bien a causa de la aplicación inadecuada de la normatividad interna e internacional existente, sin que se perciban ideas de una genuina justicia redistributiva en su ineficaz impartición, que ponga freno a la tendencia inercial de volver nugatorio este derecho humano argumentando para ello supuestos motivos económicos o presupuestales.

Tras décadas de estudio y docencia en esta disciplina y luego de haber recorrido Latinoamérica entera en tareas académicas e investigativas, no hay duda de que en todos los países de la región suele resentirse esta compleja problemática, aduciéndose casi siempre una supuesta "inviabilidad financiera" de los sistemas nacionales de seguridad social habitualmente al borde del colapso pues, sin demostrarlo fehacientemente y con una facilidad pasmosa, se propala la idea errónea de que "es ya infinanciable la seguridad social en el siglo XXI" (sic), encendiendo los focos rojos en rubros tan sensibles para la sociedad como son los servicios de salud y los subsistemas de pensiones; se hace así, en la práctica, un reduccionismo peligroso que mucho nos preocupa a los segurólogos sociales pues acorde a su naturaleza intrínseca sucede que la seguridad social es mucho más que eso, ya que implica también educación, vivienda, estancias infantiles y una serie de prestaciones sociales sin las cuales este manto protector pierde esencia y espíritu.

Lamentablemente para las sociedades de nuestra región latinoamericana, los Poderes Legislativo, Ejecutivo y Judicial nacionales no han terminado por comprender, en su quehacer cotidiano, qué es y qué significa para el país contar con sistemas nacionales sólidos de seguridad social, pues la enorme mayoría de los seguros sociales no han sido bien pensados, planeados y estructurados acordes a nuestras realidades nacionales, toda vez que sin innovar y sin imaginación alguna continúan basándose por tradición histórica en los principios de modelos históricos que antaño fueron claves para el vigente Derecho de la Seguridad Social nacional, pero que hoy día muy poco tienen que ver con la seguridad social 
contemporánea del siglo XXI: por un lado el ya mítico seguro social solidario Bismarckiano $^{1}$ de finales del siglo XIX que estuvo generalmente a proteger a los empleados públicos y ordinarios; y por la otra, pensando en la idea primigenia de la seguridad social Beveridgiana, ${ }^{2}$ que data de los años cuarenta del siglo XX, siendo esta última, sin duda alguna, la razón de la añeja aspiración — hoy tan en boga—, de crear un sistema de seguridad social universal.

Porque hoy, a la mitad de la segunda década del siglo XXI y en la denominada era del conocimiento, lo que más nos falta en Latinoamérica es cultura previsional; y claro está, no se ha generado nueva cultura porque no hay un trabajo pensado y coordinado, sólido y eficaz, en nuestros actuales planes educativos en todos los niveles para generar conciencia colectiva en el tema, pues inclusive, en nuestras propias Universidades, la confusión conceptual de directivos, profesores y alumnos es tan enorme como constante, y por ello no se termina por distinguir con claridad los elementos que integran la protección social actual.

El efecto de esa ignorancia es que hay una enorme y hasta perversa confusión conceptual, entre el sistema de la denominada protección social genérica que, para efectos propedéuticos sería "el todo" y la meta por alcanzar, en tanto que los sistemas que la integran serían tan sólo "la parte" de ese "todo", a saber: a) La seguridad social; b) la asistencia social; c) la previsión social laboral; $\mathrm{y}, d$ ) los sistemas complementarios de la protección social. ${ }^{3}$

El punto es que esos cuatro sistemas juntos — desde luego distintos todos

1 Conocido así entre los cultores de la Seguridad Social, en reconocimiento al estadista y "canciller de hierro" alemán Otto Von Bismarck, creador del primer Seguro Social del planeta entre los años 1883 a 1889. Su genial idea surgió para proteger al ejército, asegurándoles a los soldados y a sus familiares dependientes económicos que el Estado se haría cargo ante su eventual invalidez o fallecimiento, así como de sus familias; el punto resaltar es que se protegería esencialmente a los empleados subordinados, ya del propio Estado o ya del trabajo ordinario.

2 Llamado así por los segurólogos sociales en honor de Sir William Henry Beveridge, economista, y reformador social. Su principal aportación a la teoría política, económica y social es el célebre "Plan Beveridge", que sirviera de base al futuro Estado de Bienestar (welfare state), en Inglaterra. Su idea era extender la seguridad social a niños, ancianos, mujeres desamparadas dedicadas al hogar y excluidos sociales, planteando crear una seguridad social costeada vía impuestos generales.

3 Para mayores referencias acerca de tan frecuente confusión conceptual jurídica, me remito a lo expuesto en la Adenda del libro de Ángel Guillermo Ruiz Moreno intitulado: Nuevo Derecho de la Seguridad Social, $14^{\mathrm{a}}$ edición, $6^{\text {a }}$ reimpresión, Editorial Porrúa, México, 2015, pp. 931- 937. 
ellos, aunque complementarios entre sí-, integran conjuntamente lo que llamaríamos el gran sistema de la protección social nacional y, por lo tanto, son parte integrante de ese "todo" de mayor calado, en el cual se combinan armónicamente los cuatro sistemas referidos en aras de intentar proteger de mejor manera a los individuos siempre más allá de su situación productiva o laboral. A simple vista, esas figuras jurídicas — por cierto de larga data en nuestros países-, nos pueden parecer iguales, pero sucede que no son ni significan lo mismo. Si no es así en otros países de nuestra América morena, sí al menos en México. ${ }^{4}$

Un simple ejemplo, muy fácil de entender en México, lo es el tema de las jubilaciones laborales, concepto que cotidianamente se usa como sinónimo de las pensiones de seguridad social por edad o años de servicio laborados, que son en nuestra una prestación de exclusiva índole laboral y no de seguridad social; ello se constata cuando en algunos países sudamericanos se le denomina jubilaciones a las pensiones de seguridad social, y es por ello que existen Administradoras de Fondos de Jubilaciones y Pensiones (AFJP) o bien Administradoras de Fondos de Pensiones (AFP), cuando en México les llamamos simplemente Administradoras de Fondos para el Retiro (AFORE). ${ }^{5}$

En este tema trascedente - que rebasa lo meramente conceptual siempre tan complejo en razón de nuestra historia nacional e idiosincrasia jurídica propia-, la propia Organización Internacional del Trabajo (OIT), en todas sus publicaciones, hace una advertencia previa acerca del significado conceptual de las palabras y el uso particular o cotidiano que se les da en cada país... algo que, vistas las circunstancias, parece que en México no se termina todavía por captar y comprender a cabalidad. ${ }^{6}$

4 Nota: Los autores de este ensayo obviamente respetamos las ideas existentes en otros países de América Latina sobre este tema polémico, máxime que nos basamos en la normatividad vigente en nuestro país de origen, México. Más todavía, coadyuva a la continua confusión de estos conceptos jurídicos, el uso arbitrario de la clase política o de los periodistas que hacen en su peculiar forma de actuar y transmitir información al público, generándose así confusiones tan evidentes como lamentables en la población.

5 Ruiz Moreno, Ángel Guillermo. Las AFORE, el sistema de ahorro y pensiones mexicano, 6 a edición corregida y actualizada, $1^{a}$ reimpresión. Prólogo de la Dra. Patricia Kurczyn Villalobos. Editorial Porrúa, México, 2013, pp. 5-17.

6 Para más información acerca del tema de las jubilaciones laborales en México y sus diversos tipos, véase el libro de Ángel Guillermo Ruiz Moreno, intitulado: Los sistemas pensionarios de las Universidades Públicas en México, Editorial Porrúa, México, 2005, pp. 115-122. 
Otro botón de muestra claro de la confusión conceptual pre aludida y que a quienes escribimos esto tanto nos ocupa y preocupa, lo es la propia "Exposición de Motivos" de la adición hecha del artículo 353-U de la Ley Federal del Trabajo (LFT) mexicana, precepto que permite, aunque no obliga, el que los trabajadores de las universidades e instituciones de educación superior, entendido pues como un trabajo especial:"...disfrutarán de sistemas de seguridad social de seguridad social en los términos de sus leyes orgánicas o conforme a los acuerdos que con base en ellas se celebren..." (sic), facultando también a las Universidades como empleadores a "negociar" la seguridad social con sus organizaciones sindicales, a pesar de que, como luego lo veremos y demostraremos, este derecho humano es innegociable en razón de su propia naturaleza intrínseca, siendo evidente entonces la abierta inconstitucionalidad del precepto en cita. Lo demuestra la Iniciativa Presidencial del $1^{\circ}$ de octubre de 1980 de reforma y adición a la precitada LFT, cuando se adicionó al Título Sexto: de los "Trabajos Especiales", un capítulo XVII que regulase específicamente el trabajo propio de dichas Casas de Estudios Públicas, pues en lo conducente se adujo textualmente lo siguiente:

$\mathrm{Al}$ atender, por último, a los distintos regímenes de seguridad social que las instituciones ofrecen a sus trabajadores (?), se propone que en esta materia su personal se rija por lo que determina la ley que haya creado cada institución (?) o los acuerdos que con fundamento a ella se suscriban (?). Este tratamiento convalida los sistemas de protección social aplicables (?) y evita reajustes administrativos (?) que podrían entorpecer el ejercicio de los derechos adquiridos por los trabajadores (?). ${ }^{7}$

Si eso sucede en México en nuestras propias Universidades Públicas, las que se supone son "las casas del saber" y fueron creadas por el Estado para educar, imaginemos qué no puede ocurrir en tratándose de otros grupos sociales más vulnerables que el universitario; así las cosas, una de dos: Si no hay mala fe

\footnotetext{
7 Nota: Los paréntesis con signos de interrogación son nuestros. Sirva esta "joyita" de ejemplo sobre las enormes confusiones conceptuales que dicho texto legal provoca, y el evidente "manoseo" político que se da entre los Poderes Ejecutivo y Legislativo de México. El documento puede ser consultado íntegramente en el sitio web: http://www.dgelu.unam.mx/m3-1.htm (Consultado el 19 de mayo de 2016),
} 
en ello entonces hay ignorancia.

Ello es posible acaso porque intentando los Poderes Públicos a como dé lugar brindar una vida digna para todos los habitantes del país, ocurre que el pueblo soberano, quien de toda buena fe ha depositado sus esperanzas en legisladores, administradores y jueces que ignoran —o fingen ignorar, ya no se sabe — de qué se trata en el fondo éste complejo asunto de la seguridad social, la consecuencia es que terminamos todos por padecer en carne propia esa sinrazón, olvidándose que la seguridad social debe ser un natural redistribuidor de la riqueza nacional y, por ende debería impedir la pobreza y la desigualdad social.

Así las cosas, sin orden ni congruencia, sin pulcritud legislativa ni sistematización alguna, se ha hecho una especie de mezcolanza de todos los sistemas protectores del individuo entendido aquí como célula del tejido social, ello sin respetar el origen, las finalidades propias de los cuatro sistemas citados en párrafos anteriores, ni las formas de su financiamiento y la razón de ser de cada una de dichas figuras jurídicas.

No obstante, el resultado de ese peligroso "manoseo" terminológico, no ha impedido en realidad que pobreza y desigualdad sigan marcando a nuestro país y probablemente a nuestra región, convertida ya en la máxima expresión de la desigualdad en el planeta, ${ }^{8}$ con altos índices de criminalidad e inseguridad pública al tratarse de un tema de carácter estructural típico de nuestras sociedades Latinoamericanas. ${ }^{9}$

Que no nos quepa duda entonces: la seguridad social no es en realidad un tema simplemente económico, actuarial o financiero, sino más bien un asunto de un enorme trasfondo humano, que para operar de mejor manera requiere de un ingrediente esencial: voluntad política. En tiempos de tanta confusión e ignorancia, resulta pues aconsejable que los expertos en estas cuestiones tan

8 Di Virgilio, María Mercedes, y Otero y Paula Boniolo, María Pía (coordinadoras). Pobreza y desigualdad en América Latina y el Caribe. Colección CLACSO-CROP. Buenos Aires, 2011. Ver PDF en el sitio web: http:// www.crop.org/viewfile.aspx?id=278 (Consultado el 20 de mayo de 2016)

9 «Programa de Naciones Unidas para el Desarrollo» (PNUD). Informe Regional de Desarrollo Humano, 20132014. Seguridad ciudadana con rostro humano: diagnóstico y propuestas para América Latina. Ver el texto íntegro en el PDF en el sitio web:http://www.undp.org/content/dam/rblac/img/IDH/IDH-AL\%20Informe\%20 completo.pdf (Consultado el 20 de mayo de 2016) 
complejas dejen las cosas claras para evitar las manipulaciones y los usos con fines políticos de este servicio público tan trascendente para la población.

Porque finalmente, si lo que los seres humanos somos es pura y radical inseguridad desde que somos concebidos hasta después de nuestra muerte, entonces le toca al Estado como el mejor logro de la ciencia jurídica, intentar paliar hasta el límite de sus posibilidades reales, esa inseguridad permanente que padecemos todos; pero sólo se conseguirá si los representantes del Estado planifican e instrumenta inteligentemente un sistema nacional de seguridad social potente, sensato, viable y factible, en verdad comprometido con la población que al final lo financiará con gusto y gratitud.

Porque lo sepan o no, lo entiendan o no y lo quieran o no los funcionarios públicos responsables de ello, el Estado es el único garante primario y final de dicho sistema protector, ya que las tres franjas claves de seguridad que requerimos todos — esto es: seguridad nacional, seguridad pública y seguridad social - , no pueden quedar sujetas a la simple discrecionalidad del gobernante, legislador u operador de la justicia social en turno, pues su basamento tanto a nivel Constitucional como al través de los Convenios Internacionales signados y adoptados por cada uno de los países de la región, al tratarse de un derecho fundamental, no pueden quedar sujeto al capricho de nadie ni puede ser acotado o restringido a cuestiones económicas. Recordemos siempre y en todo momento los principios jurídicos clave: el de la buena fe, la solidaridad social y la convencionalidad, aplicándose éste incluso por sobre las legislaciones internas nacionales vigentes, como ya veremos y demostraremos en este ensayo. Porque en materia de seguridad social, si el Estado no puede entonces nadie puede.

\section{La débil justicia nacional y latinoamericana en temas de la seguridad social, entendida como un derecho humano.}

Por razones tanto metodológicas como de pertinencia y espacio, nos resulta imposible desarrollar aquí de manera puntual el tema de la administración de justicia en el área geográfica latinoamericana; empero, estamos nosotros convencidos de 
que si nos basamos en el sistema jurídico mexicano para intentar abordar y explicar esta temática tan trascendente que tiene que ver con la impartición de justicia social, mediante el uso del Derecho Comparado Internacional conseguirá el lector algunas luces que puedan servirles de faro y guía con objeto de contrastarlo luego con cualquier otro país de nuestra América Latina.

Pues bien de entrada diremos que en México, a la luz de los tres primeros párrafos del artículo $1^{\circ}$ de la Constitución Política de los Estados Unidos Mexicanos (CPEUM), mismo que fue reformado y adicionado el 10 de junio de 2011, la realidad nos muestra la frecuente vulneración del derecho humano de acceso al servicio público de la seguridad social—los cuales, acorde a su propia naturaleza jurídica intrínseca, se trata nada menos que de derechos irrenunciables, inalienables e inextinguibles - y, por lo tanto, su observancia es inexcusable para el Estado al tratarse de normas taxativas de evidente orden público e interés social.

En efecto, e artículo $1^{\circ}$ de nuestra CPEUM, en sus tres primeros párrafos, textualmente se establece lo siguiente:

Artículo $1^{\circ}$. En los Estados Unidos Mexicanos todas las personas gozarán de los derechos humanos reconocidos en esta Constitución y en los tratados internacionales de los que el Estado Mexicano sea parte, así como de las garantías para su protección, cuyo ejercicio no podrá restringirse ni suspenderse, salvo en los casos y bajo las condiciones que esta Constitución establece.

Las normas relativas a los derechos humanos se interpretarán de conformidad con esta Constitución y con los tratados internacionales de la materia favoreciendo en todo tiempo a las personas la protección más amplia. Todas las autoridades, en el ámbito de sus competencias, tienen la obligación de promover, respetar, proteger y garantizar los derechos humanos de conformidad con los principios de universalidad, interdependencia, indivisibilidad y progresividad. En consecuencia, el Estado deberá prevenir, investigar, sancionar y reparar las violaciones a los derechos humanos, en los términos que establezca la ley. ${ }^{10}$

Ello es así porque estamos ante la presencia no sólo de un derecho humano

10 Ver texto íntegro en el sitio web: http://www.diputados.gob.mx/LeyesBiblio/pdf/1_29ene16.pdf (Consultado el 20 de mayo de 2016) 
sino, a la par, de un derecho social exigible directamente al Estado nacional como sujeto obligado a su observancia e instrumentación; ello en base a lo estatuido en los artículos 22 y 25 de la «Declaración Universal de los Derechos Humanos» (DUDH), de la Organización de las Naciones Unidas (ONU), ${ }^{11}$ del 10 de diciembre de 1948, los cuales a la letra dicen:

Artículo 22.

Toda persona, como miembro de la sociedad, tiene derecho a la seguridad social, y a obtener, mediante el esfuerzo nacional y la cooperación internacional, habida cuenta de la organización y los recursos de cada Estado, la satisfacción de los derechos económicos, sociales y culturales, indispensables a su dignidad y al libre desarrollo de su personalidad. Artículo 25.

1. Toda persona tiene derecho a un nivel de vida adecuado que le asegure, así como a su familia, la salud y el bienestar, y en especial la alimentación, el vestido, la vivienda, la asistencia médica y los servicios sociales necesarios; tiene asimismo derecho a los seguros en caso de desempleo, enfermedad, invalidez, viudez, vejez u otros casos de pérdida de sus medios de subsistencia por circunstancias independientes de su voluntad.

2. La maternidad y la infancia tienen derecho a cuidados y asistencia especiales. Todos los niños, nacidos de matrimonio o fuera de matrimonio, tienen derecho a igual protección social.

Pues bien, del par de preceptos pre transcritos, interpretados ambos integralmente, resulta sencillo deducir del primero de ellos, artículo 22 de la DUDH:

a) Que la seguridad social es un servicio público nacional al cargo originariamente del Estado, más allá de que luego se subroguen, deleguen, concesionen o se deriven estas responsabilidades de servicios $\mathrm{y} / \mathrm{o}$ de prestaciones en dinero $o$ en especie, bien sea a entidades federativas o provincias

11 Ver texto íntegro de la DUDH y de ambos artículos, en el siguiente sitio web: http://www.ordenjuridico.gob. mx/TratInt/Derechos\%20Humanos/INST\%2000.pdf(Consultado el 20 de mayo de 2016) 
como componentes de la nación, o a empresas privadas con afanes de lucro; $y$,

b) Que es el Estado nacional - al través de sus tres Poderes: Legislativo, Ejecutivo y Judicial, desde luego cada cuál actuando en su respectivo ámbito de competencia jurídica-, el único responsable de brindarlo, siendo entonces sujeto obligado y además el garante primario y final del sistema integral de seguridad social del país. Porque es el Estado quien crea, al través de leyes, los denominados seguros sociales, que son organismos públicos descentralizados especializados, con personalidad jurídica, patrimonio propio y autarquía (órganos de gobierno propios), para brindar a nombre y en representación del Estado nacional este servicio público a la población; un servicio que por cierto no es gratuito ya que para recibirlo hay que cubrir aportaciones - la mayor de las veces tripartitas y de carácter fiscal—, para obtener dicha cobertura, sujetándose a la observancia de las bases que, para su correcta estructuración, establece el «Convenio 102 "Norma Mínima de Seguridad Social”», de la OIT. ${ }^{12}$

En tanto que, del segundo precepto pre transcrito, es decir, del artículo 25 de la DUDH, importa señalar que allí se establecen una serie de contingencias socio-vitales específicas, así como las bases mínimas que deberían contener en su creación los seguros sociales, bases establecidas sin duda con la idea de

12 Ver texto del «Convenio 102» de la Organización Internacional del Trabajo (OIT), en la web: http://www. ilo.org/dyn/normlex/es/f?p=NORMLEXPUB:12100:0::NO::P12100_INSTRUMENT_ID:312247(Consultado el 22 de mayo de 2016)

Por cierto, dicho «Convenio 102» de la OIT, está tan vigente en México, que mediante Decreto del Congreso de la Unión del 3 de diciembre de 2015, publicado en el DOFdel 18 de enero de 2016, se instituyó en nuestro país la denominada: "Semana Nacional de la Seguridad Social", a fin de generar una mayor conciencia y cultura en la población mexicana acerca de este derecho humano y social que, se insiste, es exigible directamente al Estado nacional aún y cuando los seguros sociales —ya nacionales o ya estaduales-, no satisfagan a plenitud este derecho humano, es decir, cuando se prevean riesgos sociovitales que la normatividad interna no reconozca a plenitud, siempre a condición de la forma en como cada país haya decidido aprobar la observancia del aludido «Convenio 102» de la OIT. 
propender al cuidado integral de los individuos a lo largo de su azaroso tránsito en la vida a fin de protegerles desde la cuna hasta la tumba (y de suyo hasta después de morir, al través de las pensiones y/o prestaciones médicas derivadas de la muerte del asegurado: viudez, orfandad, ascendientes, etc.). Es pues obligatorio el servicio público de la seguridad social —y también lo es para el resto de los países del área latinoamericana - pese a que por alguna razón no se encuentren contempladas el total de dichas prestaciones incluidas en el elenco de riesgos socio-vitales que establezcan las legislaciones que crean dicho seguros sociales, tal y como ocurre en México con el seguro de desempleo.

Ello es así en razón de que México adoptó el referido «Convenio 102 de la $\mathrm{OIT} »$ — que data del año 1952—, el cual se incluyó en nuestro entramado jurídico nacional desde el 12 de octubre de 1961, hallándose ahora mismo en plena vigencia. ${ }^{13}$

Por otra parte, los autores debemos dar por supuesto que algunos juristas todavía puedan pensar que la DUDH precitada no es en realidad un Tratado Internacional $\mathrm{y}$, como consecuencia de ello, tampoco sería aplicable al caso concreto del derecho humano de acceso a la seguridad social que analizamos ahora; sin embargo, no merece la pena polemizar acerca de esta cuestión planteada al resultar más que evidente acorde a los diversos estudios acerca del tema — por desgracia una temática muy poco trabajada académica y jurídicamente-, porque quienes así opinan y desde luego respetando su disenso, pasan por alto un hecho indubitable: dicha Declaración Universal en realidad no es simplemente una "declaración" muy a pesar de su propia denominación, pues es nada menos que el documento fuente de todos los Tratados Internacionales existentes en materia de los derechos humanos en el mundo. Por lo cual es fácil concluir en el sentido de que la DUDH contiene una serie de principios morales y éticos, de tan enorme fuerza e impacto en materia jurídica, que su proceso de constitucionalización fue inevitable no sólo en México y en Latinoamérica, sino también en prácticamente el planeta entero. ${ }^{14}$

13 Ver datos de vigencia del «Convenio 102» de la OIT, "Norma Mínima de Seguridad Social”: http://www.ilo. org/dyn/normlex/es/f?p=1000:11200:0::NO:11200:P11200_COUNTRY_ID:102764(Consultado el 22 de mayo de 2016)

14 Ruiz Moreno Ángel Guillermo. "La constitucionalización del Derecho Humano a la Seguridad Social 
No perdamos de vista la idea de que la provisión de los servicios públicos al cargo del Estado, están siempre estrechamente vinculados con la temática de los derechos humanos; por ende su cumplimiento, que insistimos no es discrecional, redundará en la satisfacción plena de las necesidades básicas de la gente.

Así las cosas, ante un hecho tan evidente e irrefutable como éste el que de suyo no requiere de prueba alguna para demostrarlo sino que basta con razonarlo-, cabría entonces preguntarnos: ¿se aplica en nuestro país la normatividad internacional en temas de la seguridad social, entendida como lo que en realidad es: un derecho humano? Y la respuesta, claro está, sería en sentido negativo, salvo alguna aislada excepción que terminaría por confirmarnos la regla general. Porque el Estado no imparte justicia en materia de seguridad social, sino que tan sólo se limita a aplicar a rajatabla la legislación o reglamentación nacional vigente, olvidando ponderar el inalienable derecho de acceso a este servicio público de los individuos, como si la seguridad social no fuese en realidad un derecho humano y social exigible al Estado por la vía jurisdiccional.

En ese complejo contexto planteado, para fundar y argumentar mejor el eventual reclamo de genuina impartición de justicia social, no nos queda más alternativa que recurrir a la normatividad internacional vigente para conseguir, bien sea ante los tribunales nacionales o internacionales de ser necesario, el oportuno abastecimiento de este servicio público de seguridad social — visto desde la óptica de la promoción, respeto, protección y garantía de los derechos humanos-, con la finalidad de instrumentalizar mejores prácticas nacionales tanto administrativas como jurisdiccionales, que vuelvan efectiva una correcta provisión del servicio, respetando en todo tiempo y lugar los principios básicos de universalidad, interdependencia, indivisibilidad y progresividad, propia de los derechos humanos, tal y como lo ordena el artículo $1^{\circ}$ de nuestra CPEUM.

en Latinoamérica".Revista Latinoamericana de Derecho Social. Instituto de Investigaciones Jurídicas de la UNAM. Número 19, julio-diciembre de 2014, pp. 63-86. Ver PDF en el sitio web: http://biblio.juridicas.unam. mx/revista/pdf/DerechoSocial/19/art/art3.pdf(Consultado el 22 de mayo de 2016) 


\section{La normatividad internacional de seguridad social vigente en la mayor parte de América Latina}

Pues bien, más allá de si jurídicamente es o no equivalente la DUDH a un Pacto, Convenio o Tratado Internacional en materia de derechos humanos, a manera de fundamento clave en nuestra argumentación jurídica, nos referiremos enseguida a un instrumento jurídico que resulta incuestionable y que además es de gran calado mundial: el «Pacto Internacional de Derechos Económicos Sociales y Culturales» («PIDESC») de Naciones Unidas, del cual México es un Estado Parte signante. ${ }^{15}$

El referido «PIDESC» sí que es un Tratado Internacional, obligatorio y vinculante para México - $\mathrm{y}$ de suyo prácticamente de todos los países del área Latinoamericana que lo han signado-, el cual forma parte entonces de nuestro expandido entramado jurídico normativo, al estar vigente dicho Pacto Internacional desde hace más de tres décadas y media. Al respecto no cabe duda jurídica alguna.

Ahora bien, de su valioso contenido, importa ahora traer a colación el texto íntegro de su artículo 9, el que a la letra dice:

Artículo 9. Los Estados Partes en el presente Pacto reconocen el derecho de toda persona a la seguridad social, incluso al seguro social.

Así de breve y preciso es el texto del citado artículo 9 del «PIDESC», el que no requiere de mayores comentarios, únicamente subrayando que es un "... derecho de toda persona..." — sin condicionante alguno de sexo, edad, raza, nacionalidad, estado civil, ocupación, situación migratoria, etc.-, reiterándose además el “Toda persona...", con que inicia el artículo 22 de la DUDH a cuyo texto íntegro nos remitimos en obvio de tiempo e inútiles repeticiones.

No obstante lo antes argumentado, convienen al punto algunas explicaciones que ilustren al lector o le muevan a pensar diferente acerca del tema sobre la gran

\footnotetext{
15 Dicho Pacto Internacional fue adoptado en Nueva York el 16 de diciembre de 1966 por Naciones Unidas, y México se adhirió a él desde el 23 de marzo de 1981, entrando en vigor en nuestro país mediante Decreto Promulgatorio publicado en el Diario Oficial de la Federación (DOF) del día 12 de mayo de 1981. Para ver el texto íntegro del PIDESC, consúltese el sitio web: http://www.ordenjuridico.gob.mx/TratInt/Derechos\%20 Humanos/D50.pdf(Consultado el 24 de mayo de 2016)
} 
problemática de la seguridad social contemporánea en este mundo de economía globalizada; porque como lo sostiene el Premio Nobel de Economía en 2001, Joseph E. Stiglitz: “...La desigualdad no es inevitable, ni es consecuencia de leyes inexorables de la economía. Es cuestión de políticas y estrategias. "16

Conviene precisar que en el artículo 9 del «PIDESC», también se distingue de manera clara que una cosa es la seguridad social (como enseguida veremos, se trata un concepto más bien filosófico que jurídico, al ser una aspiración humana y una meta por alcanzar, esto es, una utopía posible de materializar), y otra cosa lo es el seguro social(que es el instrumento, con una marco jurídico y normativo específico, del cual se sirve el Estado para alcanzar dicha aspiración utópica). ${ }^{17}$ Cierto es que ambos conceptos también parecen ser iguales, pero en realidad no lo son ni significan lo mismo, tal y como acontece con los cuatro distintos componentes de la protección social.

No se trata este punto de un tema menor, pues forma parte de la enorme confusión conceptual existente en México, en Latinoamérica entera e inclusive a nivel global; por lo tanto, hemos considerado la pertinencia de comentar tres ideas básicas para darle una mayor claridad al asunto del correcto abordaje de la compleja cuanto evolutiva disciplina del Derecho de la Seguridad Social contemporánea - desvinculada hoy día casi por completo del Derecho Laboral desde hace más de un cuarto de siglo, a pesar de que en la reforma laboral mexicana de diciembre de 2012 el Ejecutivo y el Legislativo federales mexicanos se empeñaron en mantenerlos unidos. ${ }^{18}$

Por ello hemos sostenido en nuestra obra escrita - coincidiendo en ello con grandes maestros iberoamericanos como el recientemente fallecido y llorado Dr. Néstor de Buen Lozano_-, que ya debería “deslaboralizarse" la seguridad

16 Stiglitz, Joseph E. La gran brecha. Qué hacer con las sociedades desiguales. Editorial Taurus. Penguin Random House Grupo Editorial, México, 2015, contraportada.

17 Para una mejor comprensión de ambos conceptos, y sobre comprender diferenciadamente el concepto de Derecho de la Seguridad Social, véase el libro de Ángel Guillermo Ruiz Moreno, intitulado:Nuevo Derecho de la Seguridad Social, 14 ${ }^{\mathrm{a}}$ edición, $6^{\mathrm{a}}$ reimpresión, Editorial Porrúa, México, 2015, pp. 27-54.

18 Esto se comienza ya a corregir de fondo, con la Iniciativa Presidencial de Reformas al artículo 123 de la CPEUM, del 28 de abril de 2016. La misma puede ser consultada en la siguiente liga web: http://es.slideshare. net/elnidodelseguro/iniciativa-de-reforma-constitucional-en-materia-de-justicia-laboral-2016 (Consultado el 2 de junio de 2016). 
social de una buena vez, por ser, en esencia, un derecho humano de todos los individuos (que acaso es el más humano de todos los derechos humanos, debido a que nos acompaña desde que somos concebidos hasta después de nuestra muerte) y, por lo tanto, no se trata de un marco protector exclusivo sólo de empleados subordinados como casi todos suponen. ${ }^{19}$

Las tres ideas referidas, muy brevemente explicadas, son las siguientes:

a) La primera idea, es que la seguridad social es un concepto abstracto de corte más bien filosófico, que vista nuestra enorme fragilidad alude a la aspiración humana de contar siempre con una especie de "red protectora en el circo de la vida", para que entre todos, de manera solidaria y con esfuerzo compartido, consigamos que el Estado nos cuide a los individuos así como a nuestras familias de una serie de contingencias socio-vitales que pudieran sufrir a lo largo de su existencia en este mundo riesgoso en que habitamos, en donde lo único seguro que tiene la vida paradójicamente es la muerte;

b) La segunda idea, es que los seguros sociales son, a la par que el antecedente primario de la actual seguridad social, sólo el instrumento del servicio público de dicha seguridad social que crea y utiliza ex profeso el propio Estado mediante decretos legislativos (entiéndase la ley-marco que regula la existencia y operación de dicho servicio público a nivel nacional o estadual). Un servicio público que —debemos de entenderlo todos-, no es un dádiva o regalo del Estado ni tampoco debe mezclarse ni confundirse con otros sistemas que integran la llamada protección social digamos genérica, compuesta como ya vimos antes de cuatro sistemas: la seguridad social

19 Ruiz Moreno, Ángel Guillermo. Seguridad Social obligatoria para trabajadores migrantes e informales. Editorial Porrúa, México, 2011, Introducción, pp. XXIII - XXXI. 
que ahora abordamos; la previsión social laboral pactada la mayor de las veces en los contratos colectivos laborales y en algunas legislaciones laborales; la asistencia social, que es donde cabe el mal denominado "Seguro Popular" junto a las dádivas vía impuestos de Programas sociales tales como la pensión a los adultos mayores; y los sistemas complementarios inherentes a la protección social genérica, como ya lo vimos en el primer apartado de este ensayo; $y$,

c) La tercera idea, que importa mucho comprenderla, es comprender a cabalidad cómo operan de manera individual y también de forma conjunta, cada uno de tales sistemas protectores pre referidos, a fin de evitar graves confusiones conceptuales, toda vez que cada uno de ellos tiene, histórica y jurídicamente, características propias de origen al cubrir finalidades distintas, y en razón de ello cuentan con un radio específico de protección, requieren requisitos distintos de acceso y otorgan diversas prestaciones - ya en dinero o ya en especie-, pero teniendo cada cuál un financiamiento particular, entes responsables de brindar prestaciones y una vía diferente para volverles exigibles. Esto nos permitirá saber de qué estamos hablando, pero sin confundir ni mezclar el uno con los otros.

Entonces, correctamente analizado este complejo asunto, como el artículo 9 del «PIDESC» no hace distingo alguno acerca de si el individuo labora en el sector formal o informal de la economía; tampoco lo hace en si se labora en un trabajo ordinario o burocrático; y no se advierte de su lacónico - y por ello extensivo texto - condiciones tales como: si se es trabajador de base o eventual, ni si se es de confianza o no, o si es migrante o su condición migratoria, ni su edad, género, raza, por lo tanto, como donde la norma no distingue no se vale distinguir, el colofón es que nos guste o no, querámoslo o no, sin excepción toda persona humana tiene derecho de acceso a la seguridad social. Por lo que resulta socialmente injusto que sea sistemáticamente inobservado ese derecho 
fundamental de manera flagrante por el Estado mediante la actuación impropia de sus tres Poderes. ${ }^{20}$

Entendámoslo de una buena vez: si vivimos en verdad en la denominada era del conocimiento, debemos todos cobrar plena conciencia de la nueva realidad y los desafíos que nos presenta problemáticas inéditas por infinidad de razones. Se trata de enterarnos del mundo en que vivimos con nuestros hijos y los hijos de ellos. Así de simple y, a la par, así de complicado el tema de fondo.

Por lo tanto, es obvio que nos encontramos ante un trato abiertamente discriminatorio en materia de seguridad social, no sólo por el Poder Ejecutivo que envía Iniciativas de leyes que inobservan lo que sus predecesores firmaron y consintieron, sino también por el Legislativo que las decreta cuando al través del Senado de la República así lo aceptaron y avalaron, y para colmo por el Poder Judicial que las aplica sin ponderación alguna y sin la plena observancia del principio jurídico pro persona que es propio de la temática de derechos humanos. Esto, en resumidas cuentas, es algo que por ignorancia supina casi nadie menciona ni cuestiona y que, por tratarse de derechos humanos cuyo pleno respeto $y$ observancia irrestricta compete al Estado, no puede ni debe ser permitido nunca y menos todavía en un Estado de Derecho como el nuestro, pues esa obligación $\mathrm{y}$ esos derechos fundamentales del gobernado se encuentran contemplados expresamente en nuestro vigente sistema jurídico nacional mexicano. Y menos todavía puede impedírsele a nadie — mexicano o no, en tanto persona humana-, el legítimo derecho de acceso a la seguridad social, puesto que se dirige a proteger nuestro ciclo vital inevitable: nacer, crecer, reproducirnos y morir.

Recordemos además que la realización de la seguridad social en México, conforme lo estatuye el artículo $3^{\circ}$ de la Ley de Seguro Social (que en enero de 1943 creó el primer organismo público descentralizado en México para brindar un servicio público especializado a la sociedad), sin excepción alguna, marca las pautas a seguir por el resto de nuestros seguros sociales — ya federales o ya

20 Este tema, por su extensión y complejidad, es imposible de abordar aquí. Al lector interesado en estas temáticas, le sugiero leer el libro de mi autoría intitulado: Seguridad Social obligatoria para trabajadores migrantes e informales, Editorial Porrúa, México, 2011.

Allí se propone crear un artículo 123-Bis a nuestra CPEUM para sentar las bases de la seguridad social del siglo XXI, y se proponen además reformas específicas a la Ley del Seguro Social, en un sistema bipartito de aportaciones a la seguridad social específico tanto para el trabajo informal, como para el tema migratorio. 
locales-, al establecer textualmente:

Artículo 3. La realización de la seguridad social está a cargo de entidades o dependencias públicas, federales o locales, y de organismos descentralizados, conforme a lo dispuesto por esta Ley y demás ordenamientos legales sobre la materia. ${ }^{21}$

Sobra realizar ya cualquier otro comentario sobre este tema, porque todo seguro social en México - lo que incluye a los 4 seguros federales y los 32 seguros o sistemas estaduales o locales-, debe seguir las misma pautas que el Instituto Mexicano del Seguro Social; y sucede que ésta legislación taxativa, de orden público e interés social, en realidad no discrimina en sus artículos 12 y 13 a quienes no son empleados subordinados porque bien pueden solicitar afiliarse voluntariamente distintos grupos sociales. ¿Por qué no lo hacen? Pues porque lo ignoran.

Así, es falsa la idea de que tan sólo los trabajadores subordinados a un empleador pueden acceder al disfrute de dicho servicio público; una disposición que establezca tales limitantes es de suyo inconstitucional al ser atentatoria del principio de progresividad de la seguridad social, porque a la luz de dicho principio y lo que implica, si hoy en ley están cubiertos digamos los trabajadores de base, la cobertura del servicio debe extenderse también a los trabajadores eventuales, a los empleados contratados a prueba o por temporada, así como a los de confianza, a todos pues porque no pueden ser discriminados.

Ahora bien, en la puntual observancia y aplicación del aludido artículo 9 del policitado «PIDESC», en su exacta observancia y seguimiento del cabal cuanto oportuno cumplimento en materia de derechos humanos relativos a la seguridad social contemplados en tal Pacto, cobra especial relevancia aquí el «Protocolo de San Salvador», ${ }^{22}$ que es como coloquialmente se le conoce al denominado: «Protocolo Adicional de la Convención Americana sobre Derechos Humanos en

21 Véase el texto íntegro del artículo $3^{\circ}$ de la Ley del Seguro Social, precepto que se halla vigente en todo el país a partir del $1^{\circ}$ de julio de 1997, en la siguiente liga web: http://www.diputados.gob.mx/LeyesBiblio/ pdf/92_121115.pdf (Consultado el 30 de mayo de 2016).

22 Para mayor información sobre este Protocolo, se sugiere ver el siguiente sitio web: http://proteo2.sre.gob.

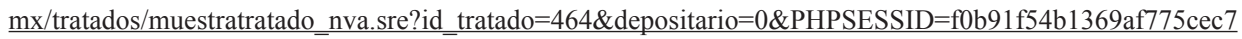
$\underline{832 \text { ba58bee }}$ (Consultado el 2 de junio de 2016) 
materia de Derechos Económicos, Sociales y Culturales», el cual fuera adoptado por la Asamblea General de Estados Americanos (OEA), en la Ciudad de San Salvador, el 17 de noviembre de 1988; importa decir que dicho Protocolo fue signado por México en esa misma fecha y ratificado formalmente el 8 de marzo de 1996, entrando en vigor en todo el país desde el 16 de noviembre de 1999.23

Ello implica que la ONU - y de manera en especial la OEA, en nuestro continente americano-- deben vigilar permanentemente al través de Informes Nacionales obligatorios las diversas materias previstas en tal Protocolo, lo que desde luego incluye al tema concreto de la seguridad social que ahora nos ocupa; se trata de monitorear los avances logrados acerca de la plena observancia y el respeto irrestricto, por parte de los Estados Miembros de ambas organizaciones internacionales en materia de los derechos humanos - tanto los económicos, como los sociales y los culturales-, a que tiene irrestricto derecho de acceso su población, así como informar acerca del cumplimento puntual por parte de todo tipo de autoridades federales, estaduales o provinciales, y hasta las municipales.

La obligación elemental de un Estado contemporáneo es precisamente esa ni más ni menos: el respeto pleno a los derechos humanos de todo individuo que se encuentre en su territorio. No hacerlo así, es violar injusta e ilegalmente el inalienable derecho de acceso al servicio público de la seguridad social, establecido tanto por los artículos 22 y 25 de la DUDH, el artículo 9 del PIDESC y, paralelamente, inobservar también el artículo 9 del «Protocolo de San Salvador», el que amplía los alcances del tema concreto relativo a la seguridad social, entendido aquí como un derecho humano, transcribiéndose enseguida dicho precepto para mayor ilustración del lector:

Artículo 9.

1. Toda persona tiene derecho a la seguridad social que la proteja contra las consecuencias de la vejez y de la incapacidad que la imposibilite física o mentalmente para obtener los medios para llevar una vida digna y decorosa. En caso de muerte del beneficiario, las

23 Ver texto íntegro del denominado «Protocolo de San Salvador», en la siguiente liga web: https://www.cidh. oas.org/basicos/Basicos4.htm (Consultado el 2 de junio de 2016) 
prestaciones de seguridad social serán aplicadas a sus dependientes.

2. Cuando se trate de personas que se encuentren trabajando, el derecho a la seguridad social cubrirá al menos la atención médica y el subsidio o jubilación en caso de accidentes de trabajo o de enfermedad profesional y, cuando se trate de mujeres, licencia retribuida por maternidad antes y después del parto.

No es necesario abundar más en el hecho de que el «Protocolo de San Salvador», es mucho más específico acerca del tema de los alcances de protección que debe tratar de conseguir la seguridad social, un asunto crucial no sólo para la propia existencia del gobernado, sino del país entero porque más que un seguro individual es un aseguramiento del grupo familiar dependiente económico (tema trascendente porque la familia es sin duda el núcleo de nuestras sociedades), y que en lo que ahora más interesa descollar, tal precepto tampoco condiciona ni hace distingo alguno en si el individuo labora en el sector formal o informal de la economía; tampoco lo hace en si se trabaja como operario del sector laboral ordinario o burocrático; o si se es trabajador de base, eventual o de confianza. Por el simple hecho de ser persona humana, puede y debe ser sujeto de aseguramiento en los Seguros Sociales nacionales. El punto clave de todo ello bien puede resumirse en pocas palabras: sin restricción alguna, todos los seres humanos tenemos derecho de acceso a la seguridad social.

\section{La impugnación de las resoluciones jurisdiccionales de seguridad social ante organismos internacionales de derechos humanos}

Sostenía el genial Albert Einstein, el científico por antonomasia del siglo XX, que lo importante era no dejar de hacerse preguntas y que: "no hay nada que sea un signo más claro de demencia, que hacer algo una y otra vez y esperar que los resultados sean diferentes.${ }^{24}$ Así, tras lo expuesto en los apartados precedentes,

24 Percy, Allan. Einstein para despistados. Soluciones atómicas para problemas relativamente graves. Ediciones De bolsillo, Penguin Random House, Grupo Editorial, México, 2014, p. 13. 
la pregunta es ya sencilla de plantear:¿cuál normativa tiene mayor jerarquía a la luz del cambio de paradigma mexicano en materia de los derechos humanos, la nacional o la internacional?

Y la respuesta correcta a tal interrogante sería, para cambiar nuestros cotidianos modos de actuar y en aras de obtener resultados diferentes, que en este mundo global en todos los órdenes del siglo XXI, impera en todo tiempo y lugar, como un derecho portable del individuo, por sobre las normas nacionales la normatividad internacional vigente en materia de los derechos humanos en tanto que favorezcan al gobernado, de acuerdo tanto al texto explícito del párrafo primero del artículo $1^{\circ}$ de nuestra CPEUM, como por el criterio de interpretación pro persona plasmado en el segundo párrafo de dicho precepto Constitucional en cita; normativas de Derecho Internacional y principio jurídico de convencionalidad que ubican, en el mismo rango jerárquico, ${ }^{25} \mathrm{a}$ los Tratados Internacionales signados por México al igual que los contemplados en nuestra propia Constitución Política federal, específicamente en tratándose de temas de derechos humanos. ${ }^{26}$

Así lo ha reconocido expresamente la Jurisprudencia emitida por el Poder Judicial de la Federación mexicano, en donde la propia Suprema Corte de Justicia de la Nación se ha pronunciado ya al respecto. ${ }^{27}$

En materia de seguridad social, para muestra bastarán un par de Tesis Aisladas, las identificadas como CVIII/2014 y la CIX/2014, dictadas ambas por la Segunda Sala de la Suprema Corte de Justicia de la Nación — que es nuestro Tribunal Constitucional mexicano- - dictadas ambas en su sesión del 15 de octubre de 2014,pues se emitieron aduciendo en su argumentación, como fundamento jurídico-normativo, el policitado «PIDESC»,y que consideramos importante

25 Véase el interesantísimo ensayo de la Ministra en Retiro Olga Sánchez Cordero, en el sitio web: http:// www2.scjn.gob.mx/Ministros/oscgv/Conf/Conf-008.htm (Consultado el 10 de junio de 2016).

26 Ello sin dejar de lado, en el caso de los operarios subordinados a un empleador, así como por el principio jurídico laboral in dubio por operario en tratándose de empleados subordinado a un patrón, en un nexo causal que opera siempre en los casos del seguro de riesgos de trabajo, ya sean accidentes o ya enfermedades profesionales derivados de tal actividad.

27 Ver texto íntegro y votación de las diversas Jurisprudencias emitidas por la Suprema Corte de Justicia de la Nación del Poder Judicial de la Federación de México, en el sitio web: http://sjf.scjn.gob.mx/sjfsist/Paginas/ DetalleGeneralScroll.aspx ?id $=41359 \&$ Clase $=$ VotosDetalleBL 
citar textualmente aquí a manera de precedente en cuanto a administración de justicia social se refiere, porque obliga al Estado mexicano, tanto para atender obligaciones inmediatas como progresivas en materia de salud, como le ordena al Estado a demostrar la eventual incapacidad de cumplir con sus obligaciones que ha contraído en materia de los derechos humanos, específicamente en materia de seguridad social.

- Época: DécimaÉpoca Registro:2007938Instancia:Segunda Sala Tipo de Tesis: Aislada Fuente: Semanario Judicial de la Federación.Publicación:viernes 14denoviembre de201409:20 h Materia(s): (Constitucional) Tesis: 2a. CVIII/2014 (10a.) SALUD.DERECHOALNIVELMÁSALTO POSIBLE.ÉSTE PUEDE COMPRENDER OBLIGACIONES INMEDIATAS, COMO DE CUMPLIMIENTO PROGRESIVO. El artículo 2 del Pacto Internacional de Derechos Económicos, Sociales y Culturales prevé obligaciones de contenido y de resultado; aquéllas, de carácter inmediato, se refieren a que los derechos se ejerciten sin discriminación y a que el Estado adopte dentro de un plazo breve medidas deliberadas, concretas y orientadas a satisfacer las obligaciones convencionales, mientras que las de resultado o mediatas, se relacionan con el principio de progresividad, el cual debe analizarse a la luz de un dispositivo de flexibilidad que refleje las realidades del mundo y las dificultades que implica para cada país asegurar la plena efectividad de los derechos económicos, sociales y culturales. En esa lógica, teniendo como referente el derecho de toda persona al disfrute del más alto nivel posible de salud física y mental contenido en el artículo 12 del citado Pacto, se impone al Estado Mexicano, por una parte, la obligación inmediata de asegurar a las personas, al menos, un nivel esencial del derecho a la salud y, por otra, una de cumplimiento progresivo, consistente en lograr su pleno ejercicio por todos 
los medios apropiados, hasta el máximo de los recursos de que disponga. De ahí que se configurará una violación directa a las obligaciones del 2 Pacto cuando, entre otras cuestiones, el Estado Mexicano no adopte medidas apropiadas de carácter legislativo, administrativo, presupuestario, judicial o de otra índole, para dar plena efectividad al derecho indicado. Amparo en revisión 378/2014. Adrián Hernández Alanís y otros. 15 de octubre de 2014. Mayoría de tres votos de los Ministros Alberto Pérez Dayán, José Fernando Franco González Salas y Luis María Aguilar Morales. Ausente: Sergio A. Valls Hernández. Disidente: Margarita Beatriz Luna Ramos. Ponente: Alberto Pérez Dayán. Secretaria: Georgina Laso de la Vega Romero.

Esta tesis se publicó el viernes 14 de noviembre de 2014 a las 09:20 horas en el Semanario Judicial de la Federación. ${ }^{28}$

- Época:Décima Época Registro:2007936Instancia:Segunda Sala Tipo de Tesis: Aislada Fuente: Semanario Judicial de la Federación Publicación: viernes 14 de noviembre de 2014 09:20 hMateria(s):(Constitucional) Tesis:2a.CIX/2014(10a.)

DERECHOS ECONÓMICOS, SOCIALES Y CULTURALES. CUANDO EL ESTADO ADUCE QUE EXISTE UNA CARENCIA PRESUPUESTARIA PARA SU REALIZACIÓN, DEBE ACREDITARLO. El contenido normativo del Pacto Internacional de Derechos Económicos, Sociales y Culturales, permite concluir que la obligación estatal de proteger, respetar y promover los derechos contenidos en ese instrumento no puede desconocer la situación particular que enfrente cada país, por lo que no existirá una violación

28 Fuente: Poder Judicial de la Federación de México. Texto de tesis consultable en el sitio web: https:// www.scjn.gob.mx/saladeprensa/Documents/Boletin/2014/PDFs/TesisSegundaSala17octal14nov2014.pdf (Consultado el 4 de junio de 2016) 
a los derechos en él tutelados, a pesar de que se acredite que un determinado derecho no ha sido realizado o alcanzado un nivel óptimo de eficacia, siempre y cuando el Estado haya demostrado que ha utilizado todos los recursos que están a su disposición en un esfuerzo por satisfacer las obligaciones establecidas en la propia convención. De ahí que no basta la simple afirmación del Estado Mexicano de que existe limitación presupuestaria para que se tenga por acreditado que ha adoptado todas las medidas "hasta el máximo de los recursos" de que disponga, para lograr la realización de los derechos consagrados en el referido Pacto, sino que para ello deberá aportar el material probatorio en que sustente su dicho. Por tal motivo, en todo asunto en el que se impugne la violación a los derechos constitucionales de la materia, los juzgadores nacionales deben distinguir entre la incapacidad real para cumplir con las obligaciones que el Estado ha contraído en materia de derechos humanos, frente a la renuencia a cumplirlas, pues es esa situación la que permitirá determinar las acciones u omisiones que constituyan una violación a tales derechos humanos. Amparo en revisión 378/2014. Adrián Hernández Alanís y otros. 15 de octubre de 2014. Mayoría de tres votos de los Ministros Alberto Pérez Dayán, José Fernando Franco González Salas y Luis María Aguilar Morales. Ausente: Sergio A. Valls Hernández. Disidente: Margarita Beatriz Luna Ramos. Ponente: Alberto Pérez Dayán. Secretaria: Georgina Laso de la Vega Romero.

Esta tesis se publicó el viernes 14 de noviembre de 2014 a las 09:20 horas en el Semanario Judicial de la Federación. ${ }^{29}$

Así de claro y así de simple en el caso de la seguridad social que ahora nos

29 Fuente: Poder Judicial de la Federación de México. Texto de tesis consultable en el sitio web: https:// www.scjn.gob.mx/saladeprensa/Documents/Boletin/2014/PDFs/TesisSegundaSala17octal14nov2014.pdf (Consultado el 11 de junio de 2016). 
ocupa, que sobra decir es precisamente un derecho humano y social que puede y debe atender el Estado mexicano — sin excusas y salvo prueba en contrario-, en todo tiempo, lugar y circunstancias. Más claro, ni el agua limpia.

Ello es así porque en la especie cobran plena aplicación las denominadas: «Reglas Operativas del Comité de Derechos Económicos Sociales y Culturales, del Consejo Económico y Social de Naciones Unidas», ${ }^{30}$ emanadas del "Comité de Derechos Económicos, Sociales y Culturales de Naciones Unidas", Reglas Operativas que por desgracia la enorme mayoría de veces es ignorada hasta por los propios operadores de la justicia en el país, pese a que ya se cumplió un lustro del cambio de paradigma jurídico en México y de donde surge la nueva Jurisprudencia de la Décima Época de nuestras Suprema Corte de Justicia, inherentes a criterios de interpretación de los alcances de los Convenios Internacionales signados y acogidos por México - criterios interpretativos todos ellos emitidos por cierto en materia de los derechos humanos, específicamente vinculados entonces al tema de acceso obligatorio a la seguridad social y a los seguros sociales mexicanos, sin excepción-.

Lo anterior, se insiste en ello, porque en nuestro país todas las personas gozarán de los derechos humanos reconocidos tanto en nuestra Constitución política como los emanados de los Tratados Internacionales de los que el Estado Mexicano sea parte, así como de las garantías para su protección, y cuyo ejercicio no podrá restringirse ni suspenderse; siempre en el entendido de que la interpretación de este tipo de derechos fundamentales se hará siempre bajo el principio protector pro persona, aplicándose en todos los casos la interpretación más favorable al gobernado. Máxime cuando se ha dejado sentado, en dicho precepto Constitucional policitado, la obligación inexcusable de que todas las autoridades, cada una en su respectivo ámbito de competencias, tienena la par la obligación de promover, respetar, proteger y garantizar los derechos humanos, siempre de conformidad con los principios de universalidad, interdependencia, indivisibilidad y progresividad que es propia de los derechos humanos.

Más todavía, para demostrarlo fehacientemente, nos remitimos al

30 Ver el contenido de dichas reglas Operativas del citado Pacto, en el siguiente sitio web: http://www. derechoshumanos.net/ONU/ComiteDerechosEconomicosSocialesCulturales-CESCR.htm(Consultado el 30 de mayo de 2016). 
Documento de Naciones Unidas, emanado del Consejo Económico Social de la ONU, al través de su "Comité de Derechos Económicos, Sociales y Culturales", asumido en su $39^{\circ}$ periodo de sesiones - efectuado en Ginebra, Suiza, del 5 al 23 de noviembre de 2007, en documento fechado el 4 de febrero de 2008-, denominado: «OBSERVACIÓN GENERAL NÚMERO 19: El derecho a la seguridad social (artículo 9)», aprobada ésta el 23 de noviembre de 2007, el cual obliga a México a rendir Informes periódicos acerca de los avances, respeto, progresividad y cumplimento en materia del servicio público de la seguridad social, tanto en su Introducción, como en su contenido normativo.

Dicho documento, que consta por cierto de 84 parágrafos numerados y se contiene en 23 páginas — por lo cual resulta materialmente imposible su trascripción literal aquí-, impone las Reglas Operativas pre referidas, en un genuino soporte jurídico internacional argumentativo de los derechos humanos que han sido cotidianamente vulnerados al resolverse todo tipo de procedimientos interpuestos en materia de la seguridad social nacional. ${ }^{31}$

Porque dichas «Reglas Operativas del Comité de Derechos Económicos Sociales y Culturales, del Consejo Económico y Social de Naciones Unidas», obligan permanentemente al Estado mexicano a revisar, actualizar y cumplir el principio de progresividad en el servicio público de la seguridad social en todo el país — esto es, tanto a nivel federal como local—,responsabilizándole al propio Estado miembro, en todos sus niveles de gobierno, de la actualización normativa y al cumplimiento cabal y oportuno de la operación de cualesquier seguro social del país al Estado Parte del «Pacto Internacional de los Derechos Económicos, Sociales y Culturales» de Naciones Unidas, es decir, a México, quien es su signante y a la par su garante.

Estamos completamente seguros que tras leer tal documento - que por cierto forma parte integrante de dicho Pacto Internacional multicitado-, se despejará cualquier duda existente, para conceder al quejoso su inalienable e irrenunciable derecho de acceso al manto protector de la seguridad social que jurisdiccionalmente suele negarse a los habitantes del país con simples evasivas

31 Ver el texto íntegro de dichas Reglas Operativas, en especial la«Observación General $N^{o} 19 »:$ "El derecho de la seguridad social, (artículo 9)", en el siguiente sitio web: http://www2.ohchr.org/english/bodies/cescr/ docs/eg/e.c.12.gc.19 sp.doc (Consultado el 5 de junio de 2016). 
y con una fundamentación y motivación legal pobre e inadecuada por obsoleta.

Así las cosas, como el Estado mexicano tiene el imperioso deber de prevenir, investigar, sancionar y en su caso reparar las violaciones a los derechos humanos, no hay pretextos que valgan, ni duda alguna en que la autoridades tanto administrativas como jurisdiccionales se equivocan, no sólo en cuanto a la aplicación de la normatividad aplicable al tema de los reclamos en cuanto a ordenar el aseguramiento a los Seguros Sociales mexicanos, sino también en la evidente interpretación errónea de la normatividad internacional vigente que obliga al Estado mexicano o a una de sus partes integrantes, a reparar cualesquier violación a nuestro inalienable derecho humano de acceso pleno e irrestricto a la seguridad social.

Por lo tanto, se concluye en este apartado que la indebida fundamentación y motivación legal, vulnera en la especie el artículo 14 de nuestra CPEUM, por lo que debe concederse a los reclamantes de su tutela, la inmediata reparación de la violación al derecho humano de acceso pleno a la seguridad social nacional, incluso por la vía de la figura jurídica de la suplencia de que adolezca la queja por tratarse de un derecho humano irrenunciable e inalienable en razón de su naturaleza intrínseca.

Por último, aunque no por ello menos importante, el Tratado Internacional denominado: «Convención Americana sobre Derechos Humanos» (CADH), de la (OEA), ${ }^{32}$ mejor conocido como «Pacto de San José», fue adoptado por los Estados Americanos el 22 de noviembre de 1969, entrando en vigor internacionalmente el 18 de julio de 1978, Convención o Pacto de calado internacional al cual se adhiriera por cierto México, acorde a las disposiciones de la Constitución federal, el 24 de marzo de 1981 y comenzando a regir en nuestro país el mismo día, atento al Decreto publicado en el DOF del 7 de mayo de 1981; y en lo que ahora más interesa destacar, reconoció expresamente la competencia contenciosa de la Corte Interamericana de los Derechos Humanos, con sede en San José, Costa Rica, para revisar y volver exigibles todos los derechos humanos civiles y políticos, conjuntamente con los derechos económicos, sociales y culturales, de

32 Para mayores datos, se sugiere al lector ver el sitio web de la Suprema Corte de Justicia de la Nación, de México en: https://www.scjn.gob.mx/libro/instrumentosconvencion/pag0259.pdf(Consultado el 5 de junio de 2016) 
los que debemos disfrutamos todos los individuos sin distingo, al ser connaturales a nuestra condición de personas humanas.

Esta vía jurisdiccional, como ya se sabe, queda expedita cuando, al ocurrir a la Comisión Interamericana de los Derechos Humanos, con sede en Washington, D.C. (Estados Unidos de Norteamérica), no satisfaga la petición del particular gobernado de manera favorable, al resolverse la Queja interpuesta por quienes se sienten afectados al no respetarse sus derechos humanos y sociales, como lo es en la temática aquí analizada de la seguridad social.

Máxime cuando nuestra propia CPEUM estatuye expresamente que es nula toda renuncia que - ya de facto o ya dejure — se haga a algún derecho consagrado en las leyes de protección del trabajador asegurado. Esa es otra razón por la que consideramos, con plena idea de la consecución de la justicia social que tanto reclama la ciudadanía en tratándose del servicio público de seguridad social que el Estado brinda a todos los trabajadores, aplicándose en la especie los artículos 44 y 46, fracción 2 en su inciso a), de la precitada «CADH», popularmente conocida como «Pacto de San José». ${ }^{33}$

Ello es así toda vez que, aun y cuando en México se reconoce la posibilidad de obtener la plena protección a los derechos humanos previstos en los Tratados Internacionales de los que es Parte signante, en la práctica se ha omitido implementar mecanismos para su eventual exigibilidad y para volverles efectivos; por lo tanto, los mexicanos se encuentran prácticamente inermes ante una legislación interna obsoleta y mal estructurada, que no contiene el debido proceso legal para alcanzar la protección del derecho humano de acceso pleno e irrestricto al servicio público de la seguridad social.

En resumen, si no dable a nivel interno la consecución del respeto y eventual reparación en esta materia, en caso necesario deberá ocurrirse entonces ante las instancias y/o tribunales internacionales para obtener la tutela de las justas peticiones planteadas, a fin no sólo de obtener justicia individual y social, sino también para sentar un precedente que les sirva a otros países de América Latina

33 Para comprender mejor este tema complejo e ignorado, se sugiere ver el PDF de la obra resumen intitulada: "Documentos Básicos en Materia de Derechos Humanos en el Sistema Interamericano", editada por la propia Corte Interamericana de Derechos Humanos (2012), en el sitio web: http://www.corteidh.or.cr/docs/libros/ docsbas2012 esp.pdf(Consultado el 11 de junio de 2016) 
que estén en igual o peor situación que la nuestra.

\section{Conclusiones}

A manera de una conclusión integral de todas las argumentaciones jurídicas anteriormente expresadas, pensamos que ha quedado ya plenamente demostrado aquí, a la luz de los criterios de interpretación pro persona que establece y ordena el segundo párrafo del artículo $1^{\circ}$ de nuestra CPEUM $-\mathrm{o}$ de ser el caso, en tratándose de empleados subordinados afiliados a los seguros sociales nacionales y/o estaduales, la aplicación oficiosa del principio jurídico in dubio pro operario clásico de la materia laboral debido al carácter tuitivo que tiene en razón de su naturaleza intrínseca-, el que el Estado Mexicano tiene la plena e inexcusable obligación de investigar, sancionar y sobre todo de reparar las eventuales violaciones a los derechos humanos de seguridad social de las que sean objeto sus ciudadanos.

Así lo establece, de forma expresa en materia de los derechos humanos, la fracción I del artículo 103 de la CPEUM que, en lo conducente y en plena concordancia con lo establecido en el artículo $1^{\circ}$ de la misma, establece con meridiana claridad lo siguiente que citamos para evitar toda duda al respecto:

Artículo 103. Los Tribunales de la Federación resolverán toda controversia que se suscite

I. Por normas generales, actos u omisiones de la autoridad que violen los derechos humanos reconocidos y las garantías otorgadas para su protección por esta Constitución, así como por los tratados internacionales de los que el Estado Mexicano sea parte; ${ }^{34}$

Entonces, jurídicamente tenemos todos los mexicanos la vía del juicio de Amparo para reclamar estos derechos humanos y sociales, de análoga manera a como se resolvieron los juicios comentados en el apartado anterior, invocándose para ello el comentado «PIDESC»y sus normas operativas precitadas como el

34 Ver el texto íntegro de dicho precepto Constitucional y las facultades señaladas en la siguiente liga web:

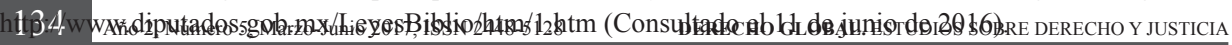


argumento primordial en la impartición de justicia en esta materia pues tiene mayor jerarquía y fuerza jurídica que las legislaciones nacionales de seguridad social.

Urge pues que tanto en México como en Latinoamérica entera, los juristas hagamos nuestra tarea, esto es, que comprendamos a cabalidad de qué se trata el derecho humano de acceso a la seguridad social y su vital importancia en nuestras respectivas patrias, para que coadyuvemos a distinguir y a diferenciar, cuándo estamos hablando de la temática inherente a la seguridad social y cuándo hablamos de temas específicos del simple asistencialismo social o de la previsión social laboral.

Y esta parte conceptual de la problemática planteada nos compete sólo a nosotros los juristas, no a los economistas ni a los financieros o actuarios, pues no se trata únicamente de un tema de dinero ni tampoco de números, sino más bien deque humanicemos este servicio público de la seguridad social poniendo siempre al individuo como prioridad, pues la seguridad social no es un gasto sino una inversión social en lo mejor de un pueblo que es su gente.

Rompamos esquemas de pensamiento, deslaboralicemos la seguridad social, y hagamos extensivo este servicio público vital a toda la población mediante un servicio público que debería ser costeado vía impuestos generales, como ya otros peritos del tema lo han propuesto.

Además, consideremos que si pese a nuestros esfuerzos académicos no ha sido posible modificar las tendencias inerciales que apuntan a la desaparición de este magnífico manto protector, sin renunciar al diálogo social entre la academia y la clase política, actuemos en consecuencia y hagamos nuestro deber al través de lograr precedentes jurisdiccionales nacionales e internacionales, en aras de contribuir al cambio de actitud de los operadores de justicia quienes tienen el ineludible deber de equilibrar y evitar la discrecionalidad de los otros dos Poderes, ya el Legislativo o ya el Ejecutivo.

Porque a fin de cuentas, de todo ello depende el futuro de nuestros sistemas nacionales latinoamericanos de seguridad social 


\section{Bibliografía}

«Convenio 102» de la OIT, "Norma Mínima de Seguridad Social", ver texto en: http://www.ilo.org/dyn/normlex/es/f?p=1000:11200:0::NO :11200:P11200_COUNTRY_ID:102764

Di Virgilio, María Mercedes, y Otero y Paula Boniolo, María Pía (coordinadoras). Pobreza y desigualdad en América Latina y el Caribe. Colección CLACSO-CROP, Buenos Aires, 2011. Ver PDF en el sitio web: http:/www.crop.org/viewfile.aspx?id=278

Percy, Allan. Einstein para despistados. Soluciones atómicas para problemas relativamente graves. Ediciones Debolsillo, Penguin Random House, Grupo Editorial, México, 2014.

Programa de Naciones Unidas para el Desarrollo (PNUD). Informe Regional de Desarrollo Humano, 2013-2014. Seguridad ciudadana con rostro humano: diagnóstico y propuestas para América Latina. Ver el texto íntegro en PDF en el sitio web:

Ruiz Moreno, Ángel Guillermo. "La constitucionalización del Derecho Humano a la Seguridad Social en Latinoamérica". Revista Latinoamericana de Derecho Social. Instituto de Investigaciones Jurídicas de la UNAM. Número 19, julio-diciembre de 2014, pp. 63 86. Ver PDF en el sitio web: http://biblio.juridicas.unam.mx/revista/ pdf/DerechoSocial/19/art/art3.pdf

Ruiz Moreno, Ángel Guillermo.Los sistemas pensionarios de las Universidades Públicas en México.Prólogo del Dr. Alberto Briceño Ruiz. Editorial Porrúa, México, 2005.

Ruiz Moreno, Ángel Guillermo. Las AFORE, el sistema de ahorro $y$ pensiones mexicano, $6^{\mathrm{a}}$ edición corregida $\mathrm{y}$ actualizada, $1^{\mathrm{a}}$ reimpresión. Prólogo de la Dra. Patricia Kurczyn Villalobos. Editorial Porrúa, México, 2013

Ruiz Moreno, Ángel Guillermo. Nuevo Derecho de la Seguridad Social, 14 a edición, $6^{\mathrm{a}}$ reimpresión. Editorial Porrúa, México, 2015. Stiglitz, Joseph E. El precio de la desigualdad. El 1 por ciento de la 
población tiene lo que el 99 por ciento necesita. Debolsillo. Penguin Random House Grupo Editorial. México, 2016.

Stiglitz, Joseph E. La gran brecha. Qué hacer con las sociedades desiguales. Editorial Taurus. Penguin Random House Grupo Editorial. México, 2015.

\section{Fuentes electrónicas consultadas:}

http:/www.ilo.org/dyn/normlex/es/f?p=NORMLEXPUB:12100:0::NO:

:P12100_INSTRUMENT_ID:312247

http://www.ordenjuridico.gob.mx/TratInt/Derechos\%20Humanos/D50.

pdf

http://es.slideshare.net/elnidodelseguro/iniciativa-de-reforma-

constitucional-en-materia-de-justicia-laboral-2016

http://www.undp.org/content/dam/rblac/img/IDH/IDH-AL\%20

Informe $\% 20$ completo.pdf

http://www.diputados.gob.mx/LeyesBiblio/pdf/92_121115.pdf

http://proteo2.sre.gob.mx/tratados/muestratratado_nva.sre?id_tratado=4

64\&depositario $=0 \&$ PHPSESSID $=$ f0b91f54b1369af775 cec $7832 \mathrm{ba} 5$

8 bee

https://www.scjn.gob.mx/saladeprensa/Documents/Boletin/2014/PDFs/

TesisSegundaSala17octal14nov2014.pdf

http://www.derechoshumanos.net/ONU/ComiteDerechosEconomicosSo

cialesCulturales-CESCR.htm

http://www2.ohchr.org/english/bodies/cescr/docs/eg/e.c.12.gc.19_sp.doc https://www.scjn.gob.mx/libro/instrumentosconvencion/pag0259.pdf http://www.corteidh.or.cr/docs/libros/docsbas2012_esp.pdf

http://www.diputados.gob.mx/LeyesBiblio/htm/1.htm

http://www.dgelu.unam.mx/m3-1.htm

https://www.cidh.oas.org/basicos/Basicos4.htm

http://sjf.scjn.gob.mx/sjfsist/Paginas/DetalleGeneralScroll.aspx?id=413

$59 \&$ Clase $=$ VotosDetalleBL 
